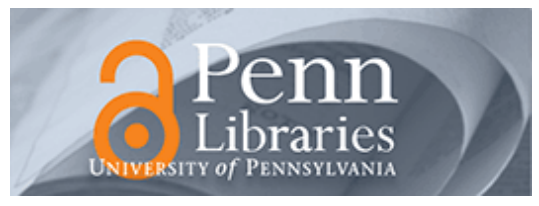

University of Pennsylvania ScholarlyCommons

$5-1-2012$

\title{
Beginning Teacher Induction: What the Data Tell Us
}

Richard Ingersoll

University of Pennsylvania, rmi@upenn.edu

Follow this and additional works at: https://repository.upenn.edu/gse_pubs

Part of the Education Commons

\section{Recommended Citation}

Ingersoll, R. (2012). Beginning Teacher Induction: What the Data Tell Us. Retrieved from https://repository.upenn.edu/gse_pubs/234

Ingersoll, R. (2012) Beginning Teacher Induction: What the Data Tell Us. Phi Delta Kappan, 93(8), 47-51.

http://www.kappanmagazine.org/content/93/8/47

Posted with permission of Phi Delta Kappa International, www.pdkintl.org. All rights reserved.

This paper is posted at ScholarlyCommons. https://repository.upenn.edu/gse_pubs/234

For more information, please contact repository@pobox.upenn.edu. 


\title{
Beginning Teacher Induction: What the Data Tell Us
}

\begin{abstract}
Induction support programs for beginning teachers is an education reform whose time has come. The national data indicate that over the past couple of decades the number of beginning teachers has ballooned in the U.S. Simultaneously, there has been a large increase in the number of states, districts, and schools offering induction programs. Importantly, the data also indicate that induction can help retain teachers, improve their instruction and their students' achievement. However, the data also tell us that the kinds and amounts of support greatly vary, and research suggests the effects depend on how much induction one gets and for how long

Disciplines

Education

\section{Comments}

Ingersoll, R. (2012) Beginning Teacher Induction: What the Data Tell Us. Phi Delta Kappan, 93(8), 47-51. http://www.kappanmagazine.org/content/93/8/47
\end{abstract}

Posted with permission of Phi Delta Kappa International, www.pdkintl.org. All rights reserved. 


\section{Beginning
teacher induction WHAT THE DATA TELL US}

\section{Induction is an education reform whose time has come.}

\section{By Richard M. Ingersoll}

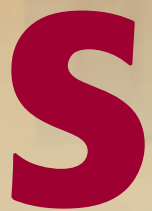

ince the advent of public schools, education commentators and reformers have perennially called

attention to the challenges encountered by newcomers to school teaching. Although elementary

and secondary teaching involves intensive interaction with youngsters, the work of teachers is done largely in isolation from colleagues. This isolation can be especially difficult for newcomers,

who, upon accepting a position in a school, are frequently left to succeed or fail on their own within the confines of their classrooms — often likened to a "lost at sea" or "sink or swim" experience. Other commentators go further, arguing that beginners tend to end up in the most challenging and difficult classroom and school assignments, akin to a "trial by fire." Indeed, some have assailed teaching as an occupation that "cannibalizes its young." These are the very kinds of issues and problems that effective employee entry, orientation, and support programs - widely known as induction — seek to address. Teaching, however, has traditionally not had the kind of induction programs for new entrants common to many skilled blue- and white-collar occupations and characteristic of many traditional professions.

This has changed in recent decades; induction for beginning teachers has become a major topic in education policy and reform. The theory behind such programs holds that teaching is complex work, that preemployment teacher preparation is rarely sufficient to provide all the knowledge and skill necessary to successful teaching, and that a significant portion of this knowledge can be acquired only on the job. This view holds that schools must provide an environment where novices

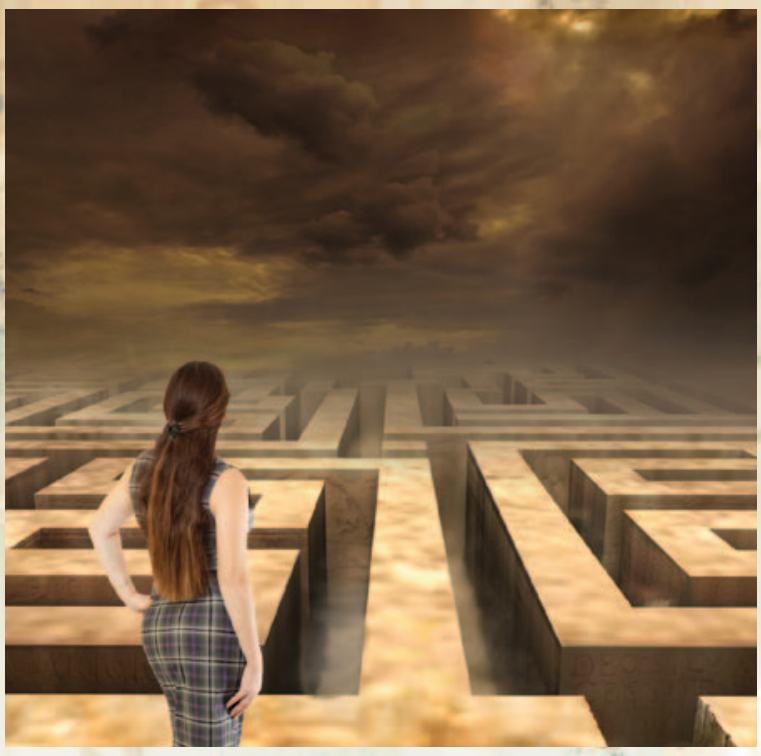
can learn how to teach, survive, and succeed as teachers. These programs aim to improve the performance and retention of new hires and to enhance the skills and prevent the loss of new teachers with the ultimate goal of improving student growth and learning.

While teacher induction has received much attention in the policy realm, until recently, empirical research on these reforms has been limited. It has been unclear how widespread induction programs are across the nation, what activities, supports, and components the induction experience usually includes, and, most importantly, whether receiving such support has any positive effect on teachers and students. All of this poses

RICHARD M. INGERSOLL (rmi@gse.upenn.edu) is a professor of education and sociology at the University of Pennsylvania, Philadelphia, $\mathrm{Pa}$. 
difficulties for those engaged in the very important and very practical matter of deciding which, if any, program or activity to offer in schools.

To answer these questions, I began a series of research projects several years ago with my colleagues Tom Smith and Michael Strong and a doctoral student, Lisa Merrill. In order to investigate the larger context surrounding teacher induction, we used the best national data available to explore demographic changes in the teaching force as a whole in recent decades. We analyzed how widespread beginning teacher induction programs are across the nation, whether their prevalence has increased over the past decade, and what types and amounts of induction beginning teachers actually get. In addition, we conducted our own statistical analysis of how participating in these induction programs affects the retention of beginning teachers. Finally, we reviewed the existing empirical studies that have evaluated the effects of induction on teachers and students.

What we learned is very revealing. Induction is a timely and growing reform, but, for those responsible for funding, designing, and implementing induction, there is both good news and sobering news.

\section{Changes in the teaching force}

For several decades, we've heard much about a "graying" trend in the teaching force. The conven- tional wisdom has been that the aging of the babyboomer generation has led to massive teacher retirements, in turn, precipitating a teacher shortage crisis. Our data analyses show that the teaching force has indeed gotten steadily older in recent decades, and this has led to more teacher retirements. But, the data also suggest that the peak of retirements may have passed; we found that the numbers of teachers retiring slowed between 2005 and 2009. In contrast, we've identified three larger, but lesser-known, changes in the demographic character of the teaching force, all of which have strong implications for induction (Ingersoll \& Merrill, 2010.)

The first trend is what we call the "ballooning" of the teaching force. After two decades of flat growth, since the mid-1980s, the teaching force in the U.S. has dramatically increased in size. The U.S. Census Bureau indicates that K-12 teaching has long been one of the largest, if not the largest, occupational groups in the nation, and it is growing even larger. In the mid-1980s, student enrollments began to grow, and they have done so ever since; the teaching force has grown at the same time. The rates of these student and teacher increases have not matched those of the post-war, baby-boom years, with one large difference: The rate of increase for teachers has far outpaced the rate of increase for students. That is, the number of teachers is going up far faster than

\section{FIG. 1.}

Years of teaching experience of public school teachers, 1987-88 and 2007-08

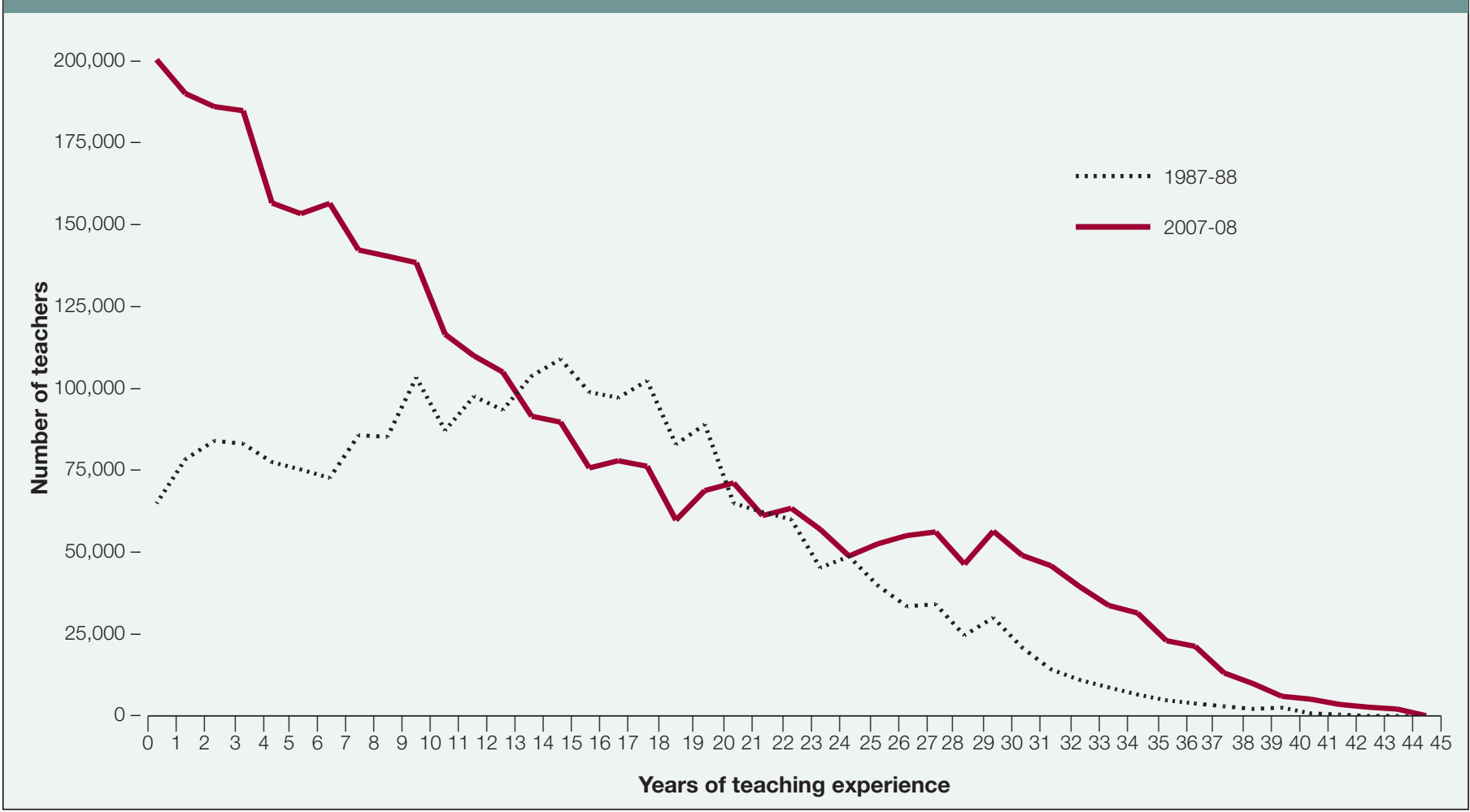


the number of students. For example, from the late 1980 s to 2008 , total K-12 student enrollment went up by $19 \%$. During the same period, the teaching force increased at over 2.5 times that rate, by $48 \%$.

This trend immediately raises two large questions: First, why? What are the reasons for and sources of the trend? What is driving this upsurge in teacher employment? And, second, what are the implications

\section{From the late 1980 s to 2008 , total K-12 student enrollment went up by $19 \%$ but the teaching force increased at over 2.5 times that rate, by $48 \%$.}

and consequences of the trend? In particular, how are school districts paying for this? We have begun to explore these questions elsewhere (Ingersoll \& Merrill, 2010). Here, we will focus on the implications of this ballooning for induction.

The ballooning has meant an upsurge in hiring and has resulted in another equally dramatic trend that we have called a "greening" of the teaching force. In 1988, there were about 65,000 first-year teachers; by 2008, this number had grown to over 200,000 (see Figure 1). In 1988, the most common teacher was a veteran with 15 years of teaching experience. By 2008, the most common teacher was not a gray-haired veteran; he or she was a beginner in the first year of teaching. By that year, a quarter of the teaching force had five years or less of experience.

A third and final trend we discovered reveals a sobering side to this greening. Teacher attrition teachers leaving teaching - is especially high in the first years on the job. Several studies, including our own analyses (Ingersoll, 2003; Ingersoll \& Perda, in press), have estimated that between $40 \%$ and $50 \%$ of new teachers leave within the first five years of entry into teaching. Moreover, we have found that the attrition rates of first-year teachers have increased by about one-third in the past two decades. So, not only are there far more beginners in the teaching force, but these beginners are less likely to stay in teaching. In short, both the number and instability of beginning teachers have been increasing in recent years.

All organizations and occupations, of course, experience some loss of new entrants - either voluntarily because newcomers decide to not remain or involuntarily because employers deem them unsuitable. Moreover, some degree of employee turnover, job, and career change is normal, inevitable, and beneficial. However, teaching has relatively high turnover compared to many other occupations and professions, such as lawyers, engineers, architects, professors, pharmacists and nurses, and these departures are not cost free (Ingersoll \& Perda, in press).

For instance, one negative consequence of the high turnover in teaching is its link to the teacher shortages that seem to annually plague many schools. In analyses of national data, we've found that neither the much-heralded mathematics and science teacher shortage (Ingersoll \& Perda, 2010) nor the minority teacher shortage (Ingersoll \& May, 2011) is primarily due to insufficient production of new teachers, as is widely believed. In contrast, the data indicate that these school staffing problems are to a significant extent the result of a "revolving door," where large numbers of teachers depart teaching long before retirement. Moreover, the data show that beginning teachers, in particular, report that one of the main factors behind their decision to depart is a lack of adequate support from school administrators (Ingersoll, 2003).

\section{Induction programs proliferate}

These demographic changes in the teaching force have large implications for induction. Our analyses show there has been a simultaneous increase in beginners and decrease in veterans. Beginners are now the largest group within one of the largest occupations in the nation, and these beginners have steadily become more prone to quickly leave teaching. All of this suggests a strong increase in the need for support programs.

Not surprisingly, our data indicate that over the past couple of decades, the number of induction programs also has grown considerably. The percentage of beginning teachers who report that they participated in some kind of induction program in their first year of teaching has steadily increased in recent

\section{FIG. 2 .}

Trends in the percent of beginning teachers participating in induction or mentor programs

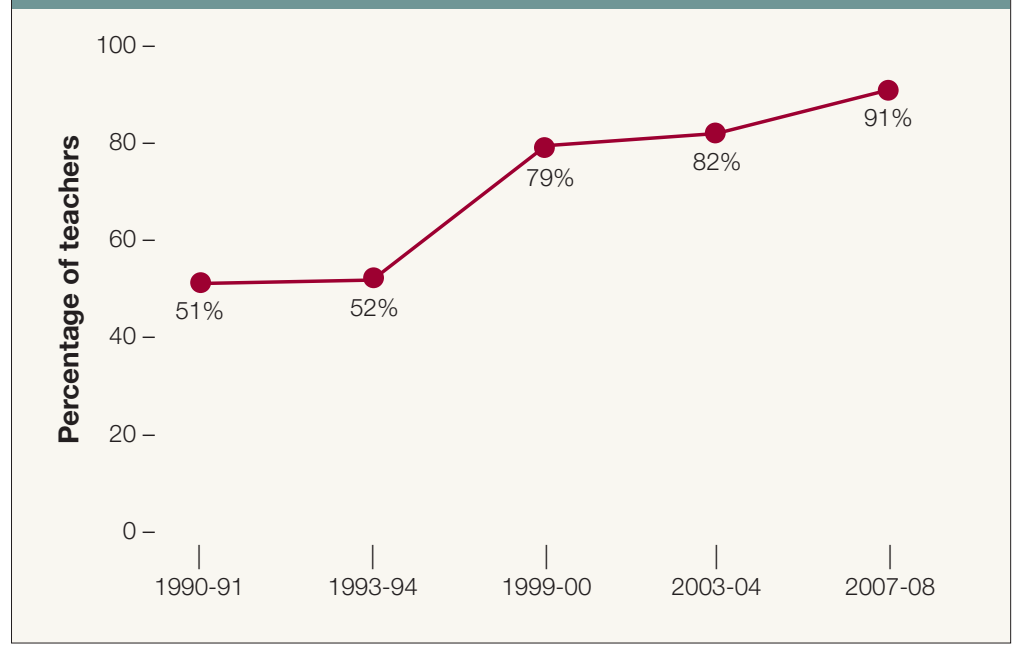


decades — from about $50 \%$ in 1990 to $91 \%$ by 2008 (see Figure 2). Moreover, these percentages don't tell the whole story. The large increase in the number of first-year teachers - the greening discussed above - has meant that, numerically, far more beginners are receiving support. In 1991, about 61,000 firstyear teachers participated in an induction or mentoring program; by 2008, this had almost trebled,

The more comprehensive the induction program, the better the retention. to about 179,000 . As of the 2010-11 school year, 27 states required some kind of induction program for new teachers (Goldrick et al., 2012).

However, while most beginning teachers now participate in some kind of formal induction program, the kinds of support that schools provide to them vary (see Figure 3). The most recent data available — from the 2007-08 school year - show that the most common induction activity that beginners participated in was having regular supportive communication with their principal, other administrators, or their department chair (87\%). Slightly fewer beginning teachers, about $80 \%$, said they received ongoing guidance and feedback from a mentor teacher. Just over half of beginning teachers said they had common collaboration and planning time with other teachers in the same subject area. Interestingly, almost one-third received extra classroom assistance, such as a teacher aide. On the other hand, fewer than $20 \%$ of beginning teachers reported receiving a reduced teaching load or schedule to ease their transition - a support that is probably more common for beginning professors in higher education.

\section{Does induction matter?}

Of course, the key question is this: Does participating in induction matter? One subset of this

\section{FIG. 3.}

Percent of 1st-year teachers who received various induction supports (2007-08)

Facetime with administrator

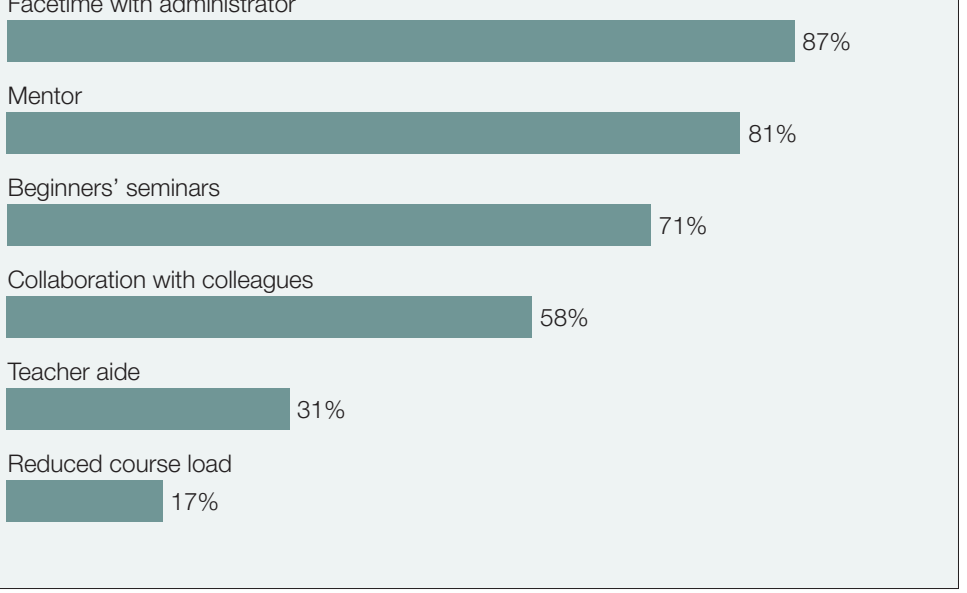

question involves retention - does participation in induction slow the high attrition of beginners? To answer this question, we undertook a series of advanced statistical analyses to examine the effect of induction on the likelihood that beginning teachers stayed in or left their schools at the end of their first year on the job (Smith \& Ingersoll, 2004; Ingersoll \& Smith, 2004).

After controlling for the background characteristics of teachers and schools, we did find a link between beginning teachers' participation in induction programs and their retention. But we also found that the strength of the effect depended on the types and number of supports that beginning teachers received. Participation in some types of activities in the first year was more effective at reducing turnover than participation in other types. The factors with the strongest effect were having a mentor teacher from one's subject area and having common planning or collaboration time with other teachers in one's subject area.

The data also revealed that the various types of induction supports, activities, or practices rarely existed alone; schools or districts usually provide beginning teachers with different "packages" or "bundles" of components or supports. Collectively, getting multiple induction components had a strong effect on whether beginning teachers stayed or left. Moreover, as the number of components in the packages increased, both the number of teachers receiving the package and the likelihood of their turnover decreased.

For example, the most common package consisted of just two basic components: working with a mentor and having regular supportive communication with one's principal, another administrator, or one's department chair. Beginners receiving just these two supports had better retention than those who received no induction at all, but the difference was small. In contrast, other beginners received a far more comprehensive package: the above two supports plus others, such as participation in a seminar for beginning teachers, common planning time with other teachers in the same subject, a reduced course load, and assistance from a classroom aide. Getting this comprehensive package had a very large effect; the likelihood that beginners who received this package would leave at the end of their first year was less than half that of those who participated in no induction activities. But only $5 \%$ of beginners received such a comprehensive package in 2007-08. Our conclusion was that induction helps, but it depends on how much one gets. The more comprehensive the induction program, the better the retention.

Our study looked at just one outcome - retention - which raises several questions. Have there been other empirical studies done on the effects of 
induction? Have any studies looked at the effect on other outcomes, such as whether participating in induction improves beginning teachers' classroom instructional practices and, in turn, improves student learning and achievement?

To answer these questions, we recently undertook a thorough review of existing empirical studies that evaluated the effects of induction (Ingersoll \& Strong, 2011). The objective of our review was to give researchers, policy makers, and educators a reliable and current assessment of what's known, and not known, about the effectiveness of teacher induction and mentoring programs. After an extensive search, we found 15 empirical studies that were solid enough to merit inclusion in our review. Each evaluated the effects of induction on an outcome, by comparing data from both participants and nonparticipants in particular induction components, activities, or programs.

When we began our review, we weren't sure what to expect. In educational research, as in many other fields, the existing base of research evaluating particular programs or reforms often yields contradictory findings and mixed conclusions. Whether the target of evaluation is a new curricular product, the value of teachers' credentials, the performance of charter schools, or whatever, typically some studies find negative effects, some find no effects, and some find positive effects. In the research on the effects of induction, we also found a few mixed and contradictory findings. But, interestingly, overall we found mostly consensus: Induction has a positive effect. Most of the studies that looked at the effect on teachers' job satisfaction, commitment, and retention found positive effects on beginning teachers who participated in some kind of induction. Likewise, most of the studies that we reviewed of teachers' classroom practices showed that beginning teachers who participated in some kind of induction performed better at various aspects of teaching, such as keeping students on task, developing workable lesson plans, using effective student questioning practices, adjusting classroom activities to meet students' interests, maintaining a positive classroom atmosphere, and demonstrating successful classroom management. Finally, for student achievement, most of the studies also showed that students of beginning teachers who participated in some kind of induction had higher scores, or gains, on academic achievement tests.

\section{Conclusion}

Induction is an education reform whose time has come. Over the past two decades, there has been a large increase in the number of states, districts, and schools offering support, guidance, and orientation programs. Importantly, the data also indicate that induction can help retain teachers and improve their instruction. The data also show that the kinds and amounts of support vary. And some research suggests that content, intensity, and duration are important: The effect depends on how much induction one gets and for how long.

Over the past couple of decades the number of beginning teachers has ballooned and so has the number of beginners eligible for induction in any given school. This is important because induction is not free-especially the more comprehensive programs. Thus far, we don't have much data and research on the relative costs and benefits of induction. Along with content and duration, induction programs also vary in their financial costs, and beyond the question of which kinds and amounts of assistance are most effective lies the question of which kinds and amounts of assistance are most cost-effective. Especially in periods of budget shortfalls, the "bang for buck" of such programs is, of course, crucial information for policy makers faced with deciding which programs to fund. This is an area in which the research community could provide useful guidance to the policy community.

\section{References}

Goldrick, L., Osta, D., Barlin, D., \& Burn, J. (2012). Review of state policies on teacher induction. Santa Cruz, CA: New Teacher Center. www.newteachercenter.org

Ingersoll, R. (2003). Is there really a teacher shortage? Philadelphia, PA: University of Pennsylvania, Consortium for Policy Research in Education.

Ingersoll, R. \& May, H. (2011). Recruitment, retention, and the minority teacher shortage. Philadelphia, PA: University of Pennsylvania, Consortium for Policy Research in Education.

Ingersoll, R. \& Merrill, L. (2010). Who's teaching our children? Educational Leadership, 67 (8), 14-20.

Ingersoll, R. \& Perda, D. (2010). Is the supply of mathematics and science teachers sufficient? American Educational Research Journal, 47 (3), 563-595.

Ingersoll, R. \& Perda, D. (in press). How high is teacher turnover and is it a problem? Philadelphia, PA: University of Pennsylvania, Consortium for Policy Research in Education.

Ingersoll, R. \& Smith, T. (2004). Do teacher induction and mentoring matter? NASSP Bulletin, 88 (638), 28-40.

Ingersoll, R. \& Strong, M. (2011). The impact of induction and mentoring for beginning teachers: A critical review of the research. Review of Educational Research, 81 (2), 201-233.

Smith, T. \& Ingersoll, R. (2004). What are the effects of induction and mentoring on beginning teacher turnover? American Educational Research Journal, 41 (3), 681-714. 